\title{
A CONTRIBUIÇÃO DE SISTEMAS DE GESTÃO À SUSTENTABILIDADE DA PRODUÇÃO DE ETANOL NO BRASIL
}

\section{THE CONTRIBUTION OF MANAGEMENT SYSTEMS TO THE SUSTAINABILITY OF ETHANOL PRODUCTION IN BRAZIL}

\author{
Cristiane Mascarenhas da Silva Sampaio' \\ Suzana Borschiver ${ }^{2}$ \\ Cláudia do Rosário Vaz Morgado ${ }^{3}$
}

RESUMO: O presente trabalho tem como objetivo apresentar a contribuição da implementação de sistemas da gestão ambiental (baseado na ABNT NBR ISO 14001) e da responsabilidade social (baseado na ABNT NBR 16001) nas empresas do setor sucroalcooleiro que buscam a demonstração da sustentabilidade de sua produção de etanol combustível. Através da correlação das normas em questão com esquemas privados de certificação, específicos para os biocombustíveis, concluiu-se que as empresas do setor que buscarem a implementação de ambos os sistemas de forma integrada, estarão em maior vantagem frente às demais.

Palavras-chave: etanol; produção sustentável; sistema da gestão ambiental; sistema da gestão da responsabilidade social; certificação.

ABSTRACT: This paper aims to present the contribution of the implementation of environmental (based on ISO 14001 standard) and social responsibility (based on the ABNT NBR 16001 standard) management systems in sugar-ethanol businesses which seek to demonstrate the sustainability of its fuel ethanol production. Through the correlation of relevant standards with private certification schemes, specific to biofuels, it was concluded that businesses in the sugar-ethanol industry that seek to implement both systems, in an integrated manner, will be at an advantage over those that do not.

Keywords: ethanol; sustainable production; environmental management system; social responsibility management system; certification.

\footnotetext{
1 Doutoranda em Tecnologia de Processos Químicos e Bioquímicos - Universidade Federal do Rio de Janeiro - UFRJ e pesquisadora do Instituto Nacional de Metrologia Normalização e Qualidade Industrial - Inmetro. E-mail: csampaio@eq.ufrj.br. ${ }^{2}$ Doutora em Engenharia Química - UFRJ, professora associada da Escola de Química - UFRJ e Coordenadora do Núcleo de Estudos Industriais e Tecnológicos - NEITEC. E-mail: suzana@eq.ufrj.br.

${ }^{3}$ Doutora em Engenharia de Produção - UFRJ, professora associada da Escola Politécnica - UFRJ e Coordenadora do Programa de Recursos Humanos - ANP/MCT (PRH41- Engenharia Ambiental na Indústria do Petróleo, Gás e Biocombustíveis). E-mail: cmorgado@poli.ufrj.br.
} 


\section{INTRODUÇÃO}

Vários movimentos mundiais podem ser apontados como indicadores de ações voltadas para 0 desenvolvimento sustentável.

Em fevereiro de 2010, o Conselho Empresarial Mundial para $\circ$ Desenvolvimento Sustentável (WBCSD) publicou o relatório Vision 2050, o qual oferece um panorama de como estará a população e o planeta nas próximas quatro décadas, e tem, por principal finalidade, incitar o diálogo e a interação entre as empresas, sociedade civil e governos, em busca de estratégias e ações para concretizar um mundo sustentável (CEBDS, 2010).

Neste ano, 2012, ocorreu a Rio +20 (Conferência das Nações Unidas sobre desenvolvimento sustentável), evento que marcou os 20 anos da Eco 92, e cujos objetivos principais foram assegurar um compromisso político renovado para com o desenvolvimento sustentável, avaliar o progresso alcançado $\mathrm{e}$ as lacunas na implementação e, enfrentar os novos e emergentes desafios (ORGANIZAÇÃO DAS NAÇÕES UNIDAS, 2012).

Diante desses fatos, percebe-se que as empresas, que não se envolverem nesse movimento, estarão em forte descompasso com a realidade, pondo em risco, inclusive, sua permanência no mercado.

Em relação ao setor sucroalcooleiro brasileiro, sabe-se que esse setor tem sido alvo de diversos questionamentos, tanto no âmbito internacional quanto nacional, em relação à produção sustentável de etanol a partir da cana-de-açúcar; biocombustível com reconhecida vantagem energética e baixa emissão de Gases de Efeito Estufa (GEE) (MACEDO, 2007; FAPESP, 2010).
Para enfrentar tais questionamentos, algumas empresas do setor vêm investindo na certificação de sua produção, com base em esquemas (ou sistemas) privados, os quais têm por objetivo demonstrar que a empresa atua de forma responsável, respeitando os três pilares da sustentabilidade: ambiental, social e econômico (POPE et. al., 2004).

Outras formas, possíveis de demonstrar compromisso com a busca pela sustentabilidade de seus processos, seriam a implementação de sistemas de gestão com base nas normas ABNT NBR ISO 14001 (Sistemas da gestão ambiental) e ABNT NBR 16001 (Responsabilidade social), podendo-se, a critério da empresa, chegar a uma certificação voluntária com base nessas normas. A certificação é um dos mecanismos mais usados para demonstrar que requisitos especificados relativos a um produto, processo, sistema, pessoa ou organismo são atendidos e, quando baseada em normas internacionais (ou seja, elaboradas em fóruns internacionais como a International Organization for Standardization - ISO), e conduzida por organismo de "terceira parte" (com independência entre as partes: cliente e fornecedor), acreditado por órgão com o devido reconhecimento nos fóruns correlatos, configura-se em um importante instrumento para o estabelecimento de acordos de reconhecimento mútuo e acesso a mercados mais rigorosos (ABNT, 2005; INMETRO, 2007).

Recentemente, foi criado, no âmbito da ISO, um Comitê técnico para desenvolver uma norma internacional sobre "Critérios de sustentabilidade para a bioenergia" (TC 248), a qual pode representar, concretamente, uma forma de facilitar a exportação do etanol brasileiro. 


\section{O MERCADO PARA O ETANOL COMBUSTÍVEL BRASILEIRO}

O Brasil é o segundo maior produtor de etanol mundial, utilizando cana-de-açúcar como matéria-prima. Na safra 2010/2011, foram produzidos 27,6 bilhões de litros de etanol em 437 usinas (COMPANHIA NACIONAL DE ABASTECIMENTO, 2011; BRASIL. MINISTÉRIO DO DESENVOLVIMENTO, 2012).

Nos últimos anos, o foco da indústria brasileira tem sido o mercado doméstico, impulsionado, principalmente, pelo crescimento das vendas de veículos flex, os quais foram os responsáveis pelo renascimento do mercado de álcool combustível no país.

Apesar do volume de produção expressivo, verificou-se, na safra de 2010/2011, uma demanda interna maior do que o setor foi capaz de atender. Com o volume de etanol estocado reduzido, devido à forte estiagem, e, também, à supervalorização do açúcar no mercado internacional (o que, mais uma vez, ocasionou uma produção preferencial deste em detrimento do etanol), houve um desabastecimento do mercado nacional e consequente elevação do custo do etanol para o consumidor final, não sendo esse produto mais vantajoso em relação à gasolina.

Quanto às exportações, o ano de 2008 foi emblemático, tendo o Brasil exportado um volume recorde de etanol: 5,12 bilhões de litros (BRASIL. MINISTÉRIO DO DESENVOLVIMENTO, 2012). Contudo, as vendas externas brasileiras permanecem limitadas, em parte, por tarifas elevadas e barreiras não-tarifárias, aplicadas por nações desenvolvidas, como é o caso do mercado europeu. Além desses empecilhos, a crise financeira de 2008 e a supervalorização do açúcar, colaboraram para que as exportações brasileiras de etanol, em 2009, fossem, substancialmente, reduzidas (uma redução de $36 \%$ em relação a 2008), e permanecessem em queda nos anos posteriores (BRASIL. MINISTÉRIO DO DESENVOLVIMENTO, 2012).

Apesar da queda nas exportações, o cenário mundial aponta possibilidades significativas para elevar 0 volume exportado.

Os Estados Unidos anunciaram, no início de 2007, que pretendem substituir, até 2017, 20\% dos combustíveis fósseis por biocombustíveis (GORREN, 2009). Nesse mesmo ano, foi publicada a Lei Federal Energy Independency and Security Act (EISA), cujo principal objetivo é a segurança energética do país, via redução da dependência do petróleo e diversificação da matriz energética, mas também busca reduzir as emissões de GEE. Nessa Lei, destaca-se o Renewable Fuel Standard revisado (RFS2), o qual estendeu a demanda por biocombustíveis para 136 bilhões de litros, em 2022 (CGEE, 2009). Adicionalmente, às legislações citadas, os EUA não renovaram, no final de 2011, a tarifa sobre as importações de etanol e os pesados subsídios à indústria norteamericana, medida há muito requerida pelo Brasil (EUA..., 2011).

Em abril de 2009, a União Europeia (UE) publicou Diretiva (2009/28/CE), cujo objetivo é alcançar, até 2020, uma quota de $20 \%$ de energia proveniente de fontes renováveis, no consumo final bruto de energia da Comunidade Europeia (CE), e uma quota de $10 \%$ de energia renovável nos transportes (UE, 2009). Prevê-se que grande parte desses $10 \%$ seja cumprida 
pelo uso de biocombustíveis, o que pode representar um mercado de, aproximadamente, 22 bilhões de litros de etanol por ano (KUTAS; ZECHIN, 2008).

Diante desses fatos, evidencia-se a existência de um mercado em potencial para o etanol, em particular o produzido no Brasil.

Entretanto, apesar desse cenário favorável ao etanol brasileiro, diversas manifestações surgiram, principalmente na Europa, contra a importação desse produto, alegando danos ao meio ambiente, competição com os alimentos e violação de direitos humanos em sua produção (PETERSEN, 2008; VALOR, 2008). Devido a pressões de grupos ambientalistas e de produtores europeus de biocombustíveis, receosos de sua baixa competitividade, a UE incluiu, no texto da Diretiva 2009/28/CE, a exigência de certificação socioambiental tanto para os biocombustíveis produzidos na CE quanto para os importados (UE, 2009).

Dessa forma, somente 0 etanol produzido de forma comprovadamente sustentável alcançará os mercados mais rigorosos.

Assim, como anteriormente citado, empresas do setor sucroalcooleiro brasileiro vêm buscando a certificação de sua produção de etanol, utilizando-se de esquemas voluntários privados, que estabelecem normas para a produção sustentável de biocombustíveis, mais adequadamente denominadas "protocolos".

\section{CERTIFICAÇÕES PRIVADAS DISPO- NÍVEIS PARA DEMONSTRAR PRODUÇÃO SUSTENTÁVEL}

A CE incentivou, por meio da Diretiva 2009/28/CE, empresas, Governos e ONGs a criarem esquemas voluntários para a certificação de biocombustíveis. A Comunidade estabeleceu, ainda, uma sistemática para avaliar a confiabilidade desses esquemas, bem como se sua auditoria está à prova de fraudes. Todos devem ter auditores independentes que inspecionem toda a cadeia de produção, do agricultor ao comerciante e ao fornecedor de combustível. Os certificados emitidos devem garantir que todos os biocombustíveis avaliados são sustentáveis e produzidos respeitando os critérios estabelecidos na Diretiva. Entretanto, o reconhecimento da CE não garante que outros blocos/países também reconhecerão o esquema.

Alguns dos esquemas de certificação privados, mais amplamente divulgados, são apresentados a seguir:

- Roundtable on Sustainable Biofuels (RSB), uma iniciativa da École Polytechnique Fédérale de Lausanne (EPFL), na Suíça, liderada por seu Centro de Energia, publicada em 2010 (ÉCOLE POLYTECHNIQUE FÉDÉRALE DE LAUSANNE, 2011);

- International Sustainability and Carbon Certification (ISCC), iniciativa encomendada pela Agência Federal para Agricultura e Alimentação Alemã (BLE), publicada em 2010 (INTERNATIONAL SUSTAINABILITY AND CARBON CERTIFICATION SYSTEM, 2011); e

- Bonsucro (Better Sugar Cane Initiative), elaborado pela organização inglesa de mesmo nome, publicado em 2011. Entre seus membros estão organizações não-governamentais como a WWF, Ethical Sugar e Solidaridad e várias empresas (nacionais e estrangeiras) do setor (inclusive a UNICA) (BONSUCRO, 2011). 
Os dois primeiros aplicam-se a todos os biocombustíveis e biomassas para originá-los. Já, o Bonsucro, além de ser específico para a produção de etanol a partir da cana-de-açúcar, engloba, também, a avaliação da sustentabilidade da produção do açúcar. Todos estão estruturados na forma de Princípios, Critérios e Indicadores, os quais abrangem os aspectos ambientais, sociais e econômicos para uma produção sustentável. A Tabela 1 apresenta as características estruturais de cada protocolo, relativo à produção sustentável, dos esquemas citados.

Tabela 1 - Número de Princípios, Critérios e Indicadores de cada Protocolo

\begin{tabular}{cccc}
\hline Protocolo & Princípios & Critérios & Indicadores \\
\hline Bonsucro & 6 & 22 & 50 \\
ISCC & 6 & 92 & - \\
RSB & 12 & 37 & 217 \\
\hline
\end{tabular}

(*) Além dos 5 Princípios oficialmente declarados como tal, contabilizou-se a seção 6 (Requisitos da Diretiva 2009/28/CE) e seus respectivos critérios e indicadores, uma vez que nos demais protocolos os requisitos da Diretiva constam dentro dos Princípios.

\subsection{Princípios Comuns aos Protocolos Privados}

Buscou-se correlacionar os três protocolos citados, visando a identificar os princípios comuns entre eles. Para tal, optou-se por manter os Princípios do protocolo Bonsucro, em ordem crescente, e correlacioná-los com os Princípios dos demais, o que lhes ocasionou a desordem numérica. $O$ resultado de tal análise permitiu constatar, de forma preliminar, aqueles requisitos primordiais que a produção de etanol brasileiro deve atender para alcançar o mercado europeu. A Tabela 2 apresenta o resultado da correlação.

\section{Tabela 2 - Correlação dos Princípios dos Protocolos privados}

\begin{tabular}{|c|c|c|}
\hline BONSUCRO & ISCC & RSB \\
\hline 1- Cumprir a Lei & $\begin{array}{l}\text { 5- A produção de biomassa } \\
\text { deve ser efetuada em } \\
\text { conformidade com todas as leis } \\
\text { regionais e nacionais e deve } \\
\text { seguir os tratados internacionais } \\
\text { relevantes. }\end{array}$ & $\begin{array}{l}\text { 1- Operações de biocombustíveis devem } \\
\text { seguir todas as leis e regulamentos } \\
\text { aplicáveis. } \\
\text { 12- Operações de biocombustíveis devem } \\
\text { respeitar os direitos à terra e os direitos de } \\
\text { uso da terra. }\end{array}$ \\
\hline $\begin{array}{l}\text { 2- Respeitar os } \\
\text { direitos humanos e } \\
\text { trabalhistas. }\end{array}$ & $\begin{array}{l}\text { 3- Condições de trabalho } \\
\text { seguras por intermédio de } \\
\text { treinamento e educação, o uso } \\
\text { de roupas de proteção e } \\
\text { assistência apropriada e } \\
\text { oportuna em caso de acidentes. } \\
\text { 4- A produção de biomassa não } \\
\text { deve violar os direitos humanos, } \\
\text { direitos trabalhistas ou direitos } \\
\text { sobre a terra. Deve promover } \\
\text { condições de trabalho } \\
\text { responsável e a saúde dos } \\
\text { trabalhadores, a segurança e o } \\
\text { bem-estar e deve ser baseada }\end{array}$ & $\begin{array}{l}\text { 4- Operações de biocombustíveis não } \\
\text { devem violar os direitos humanos ou } \\
\text { direitos trabalhistas, e devem promover o } \\
\text { trabalho decente e o bem-estar dos } \\
\text { trabalhadores. }\end{array}$ \\
\hline
\end{tabular}




\section{3- Gerenciar eficiências de insumos, produção e processamento de modo a aumentar a sustentabilidade.}

5- Melhorar constantemente as áreas-chave do negócio.
6- Cumprimento da Diretiva da UE 2009/28/EC em relações responsáveis com a comunidade.

6- Boas práticas de gestão devem ser implementadas.

2- Biomassas devem ser produzidas de forma ambientalmente responsável. Isso inclui a proteção do solo, água e ar e a aplicação de Boas Práticas Agrícolas.

6- Boas práticas de gestão devem ser implementadas.

1- Biomassas não devem ser produzidas em terra com alto índice de biodiversidade ou elevado teor de carbono (HCV). Áreas com HCV devem ser protegidas.

Obs: Quanto ao cálculo das emissões de GEE, o ISCC, publicou protocolo específico com a metodologia (ISCC_EU_205_GHG_Emission s_Calculation_Methodology_an d_GHG_Audit_2.3_eng)
2- Operações sustentáveis de biocombustíveis devem ser planejadas, implementadas e continuamente melhoradas por meio de uma avaliação de impacto, de um processo de gestão e de uma análise de viabilidade econômica abertos, transparentes e consultivos. 11- A utilização de tecnologias em operações de biocombustíveis deve procurar maximizar a eficiência da produção e do desempenho social e ambiental, e minimizar o risco de danos ao meio ambiente e às pessoas.

7- Operações de biocombustíveis devem evitar impactos negativos na biodiversidade, ecossistemas e valores de conservação.

8- Operações de biocombustíveis devem implementar práticas que busquem reverter a degradação do solo e/ou manter a saúde do solo.

9- Operações de biocombustíveis devem manter ou ampliar a qualidade e a quantidade dos recursos hídricos superficiais e do solo, e respeitar os direitos formais prévios ou costumeiros à água.

10- Poluição atmosférica proveniente das operações de biocombustíveis deve ser minimizada ao longo da cadeia de suprimentos.

2- Operações sustentáveis de biocombustíveis devem ser planejadas, implementadas e continuamente melhoradas por intermédio de uma avaliação de impacto, de um processo de gestão e de uma análise de viabilidade econômica abertos, transparentes e consultivos.

11- A utilização de tecnologias em operações de biocombustíveis deve procurar maximizar a eficiência da produção e do desempenho social e ambiental, e minimizar o risco de danos ao meio ambiente e às pessoas.

3- Biocombustíveis devem contribuir para a mitigação das mudanças climáticas, reduzindo significativamente o ciclo de vida das emissões de GEE em comparação aos combustíveis fósseis.

7- Operações de biocombustíveis devem evitar impactos negativos na biodiversidade, ecossistemas e valores de conservação. 
5- Em regiões de pobreza, as operações de biocombustíveis deverão contribuir para o desenvolvimento social e econômico do local, de populações rurais e indígenas e das comunidades.

6- Operações de biocombustíveis devem assegurar o direito humano à alimentação adequada e melhorar a segurança alimentar nas regiões de insegurança alimentar.

Elaboração própria com base nos seguintes documentos:

Bonsucro: versão 3 - Março de 2011. (BONSUCRO_Production_Standard_PT)

ISCC: versão 2.3-EU - 11-03-15 (ISCC_EU_202_Sustainability Requirements for the Production of Biomass 2.3

RSB: versão 2.0 (10 May 2011-RSB-STD-11-001-01-001 - Consolidated RSB EU RED Principles \& Criteria)

versão 2.0 (13 Dec 2010 - RSB-IND-11-001-20-001 - Consolidated RSB EU RED Indicators to Principles \& Criteria)

Verificou-se que, apesar dos continuamente, visando, sempre, à protocolos apresentarem números variados prevenção da poluição. A implementação do de Princípios e redações distintas, foi SGA possibilita identificar desperdícios e possível identificar exigências similares processos ineficientes, otimizando o uso de entre eles, com exceção dos princípios cinco (5) e seis (6) do RSB. Dessa forma, constatou-se que há equivalência até 0 princípio 6 do Bonsucro.

4. CONTRIBUIÇÕES DA IMPLEMENTAÇÃO DE SISTEMAS DE GESTÃO AMBIENTAL E DA RESPONSABILIDADE SOCIAL

A implementação de sistemas de gestão (SG), com base nas normas ABNT NBR ISO 14001:2004 (Sistemas da gestão ambiental - SGA) e ABNT NBR 16001:2004 (Sistema da gestão da Responsabilidade social - SGRS), também se configura em uma forma das empresas do setor sucroalcooleiro demonstrarem compromisso com as questões socioambientais.

As empresas que buscam um SGA, com base na ISO 14001, beneficiam-se de várias maneiras, pois passam a ter um maior controle de seu processo, reavaliando-o, matérias-primas, diminuindo o consumo de energia e recursos hídricos e a produção de resíduos. Com isso, a empresa estará se antecipando a fiscalizações pelos órgãos ambientais, reduzindo riscos de responsabilização por danos ambientais e penalidades. As organizações se beneficiam, ainda, pela criação de uma imagem "verde" e acesso a novos mercados (VALLE, 1995 apud DENARDIN; VINTER, 2011).

Similarmente, as empresas que buscam a implementação de um SGRS com base na NBR 16001, poderão ser beneficiadas em vários aspectos, como: maior vantagem competitiva; reputação; capacidade de atrair e manter trabalhadores ou sócios, clientes; melhor relacionamento com outras empresas, governos, mídia, fornecedores e a comunidade em que atua.

A gestão socialmente responsável pode ser entendida como um caminho encontrado pelas empresas para estreitar os 
laços com os diversos públicos de interesse que compõem o leque de relacionamento da Companhia. Sua adoção implica a criação de um ferramental adequado para a conformação de conflitos e tensões, resultantes de um cenário marcado por intensa competitividade entre as corporações, pressões decorrentes de setores organizados da sociedade e pelas dificuldades em produzir mais, e ao mesmo tempo, atendendo legislações cada vez mais rigorosas (SAID, 2008).

Como toda norma de gestão, tanto a ISO 14001 quanto a NBR 16001 não estabelecem critérios específicos de desempenho ambiental e da responsabilidade social, respectivamente, e sim requisitos mínimos relativos a um SGA e a um SGRS. Esse tipo de abordagem parece um tanto branda inicialmente, mas é - que permite que as normas sejam aplicáveis a qualquer organização que deseje, independente do porte.

Outro motivo do não estabelecimento de critérios específicos de desempenho, mesmo sendo uma norma sujeita à auditoria por uma terceira parte, é que as normas ISO devem respeitar 0 direito à soberania nacional, cultuado nos acordos da Organização Mundial do Comércio (OMC) (HARRINGTON; KNIGHT, 2001).

Já é prática das empresas de maior porte adotarem um Sistema de Gestão Integrada (SGI), baseado, por exemplo, nas normas ABNT NBR ISO 9001 e ABNT NBR ISO 14001. A inclusão da ABNT NBR 16001 no SGI, tornaria o sistema mais completo e permitiria às empresas que 0 incorporassem, além de um menor custo, um maior diferencial competitivo. A integração é claramente possível, uma vez que ambas as normas são baseadas na metodologia Plan-Do-Check-Act (PDCA) (Planejar-Fazer-Verificar-Atuar), a qual tem como foco a melhoria contínua dos respectivos SG. A Tabela 3 fornece informações sobre a estrutura das normas em questão. 
Tabela 3 - Requisitos dos Sistemas de Gestão ambiental e da Responsabilidade Social

\begin{tabular}{|c|c|c|c|}
\hline ABNT NBR ISO 14001:2004 & & & ABNT NBR 16001:2004 \\
\hline Requisitos do SGA & 4 & 3 & Requisitos do SGRS \\
\hline Requisitos gerais & 4.1 & 3.1 & Requisitos gerais \\
\hline Política Ambiental & 4.2 & 3.2 & Política da Responsabilidade social \\
\hline Planejamento & 4.3 & 3.3 & Planejamento \\
\hline Aspectos ambientais & 4.3.1 & 3.3.1 & Aspectos da responsabilidade social \\
\hline Requisitos legais e outros & 4.3.2 & 3.3.2 & Requisitos legais e outros \\
\hline Objetivos, metas e programa(s) & 4.3 .3 & 3.3.3 & Objetivos, metas e programas \\
\hline Implementação e operação & 4.4 & 3.4 & Implementação e operação \\
\hline $\begin{array}{l}\text { Recursos, funções, responsa- } \\
\text { bilidades e autoridades }\end{array}$ & 4.4.1 & 3.3.4 & $\begin{array}{l}\text { Recursos, regras, responsabilidades } \\
\text { e autoridade }\end{array}$ \\
\hline $\begin{array}{ll}\text { Competência, } & \text { treinamento } \\
\text { conscientização } & \text { e } \\
\text { Comunicação } & \end{array}$ & $\begin{array}{l}4.4 .2 \\
4.4 .3\end{array}$ & $\begin{array}{l}3.4 .1 \\
3.4 .2\end{array}$ & $\begin{array}{l}\text { Competência, } \\
\text { conscientização } \\
\text { Comunicação }\end{array}$ \\
\hline Documentação & 4.4.4 & 3.5 & Requisitos de documentação \\
\hline Controle de documentos & 4.4 .5 & 3.5 .3 & Controle de documentos \\
\hline Controle operacional & 4.4 .6 & 3.4 .3 & Controle operacional \\
\hline $\begin{array}{llll}\begin{array}{l}\text { Preparação } \\
\text { emergências }\end{array} & \text { e } & \text { resposta } & \text { a }\end{array}$ & 4.4.7 & & \\
\hline Verificação & 4.5 & 3.6 & Medição, análise e melhoria \\
\hline Monitoramento e medição & 4.5.1 & 3.6 .1 & Monitoramento e medição \\
\hline $\begin{array}{l}\text { Avaliação do atendimento a } \\
\text { requisitos legais e outros }\end{array}$ & 4.5.2 & 3.6 .2 & Avaliação da Conformidade \\
\hline $\begin{array}{l}\text { Não-conformidade, ação corretiva } \\
\text { e ação preventiva }\end{array}$ & 4.5 .3 & 3.6 .3 & $\begin{array}{l}\text { Não-conformidade e ações corretiva } \\
\text { e preventiva }\end{array}$ \\
\hline Controle de registros & 4.5.4 & 3.5.4 & Controle de registros \\
\hline Auditoria interna & 4.5 .5 & 3.6.4 & Auditoria interna \\
\hline Análise pela administração & 4.6 & 3.6 .6 & Análise pela Alta administração \\
\hline
\end{tabular}

Elaborada pelas autoras com base nas respectivas normas.

O que norteia ambos os sistemas é o estabelecimento, pela empresa, de uma política que leve em conta requisitos legais e outros que julgar relevantes. Cada política é específica ao tipo de SG, entretanto devem englobar requisitos comuns, como um comprometimento com a melhoria contínua, além de fornecer uma estrutura para o estabelecimento e revisão dos objetivos e metas ambientais e da responsabilidade social, respectivamente.

Outro ponto crucial dos dois sistemas é a identificação dos "aspectos" que possam ser controlados e aqueles que a organização tenha influência, a fim de determinar os que tenham ou possam ter impactos significativos (positivos ou negativos). Segundo a NBR ISO 14001, aspecto ambiental é o elemento das atividades ou produtos ou serviços de uma organização que pode interagir com o meio ambiente (ABNT, 2004a); já, segundo a NBR 16001, aspecto da responsabilidade social é o elemento das relações, processos, produtos e serviços de uma organização, que podem interagir com o meio ambiente, contexto econômico e contexto social (ABNT, 2004b). A identificação desses aspectos deve ser realizada por intermédio do estabelecimento, implementação e manutenção de procedimento(s).

Ambos os sistemas, ainda, exigem 
que a empresa estabeleça, implemente e mantenha procedimento(s) para identificar e ter acesso a requisitos legais aplicáveis e a outros subscritos pela empresa, relacionados aos seus aspectos, além de avaliar, periodicamente, o atendimento a tais requisitos, mantendo, inclusive, registros dos resultados das avaliações.

No entanto, verifica-se, justamente pela natureza do tema em questão, que a NBR 16001 exige da organização, desde o levantamento dos "aspectos", a identificação das partes interessadas e suas percepções, as quais também terão papel fundamental para o estabelecimento, implementação e manutenção dos objetivos e metas do sistema. Percebe-se, ainda, que a NBR 16001 especifica o mínimo que deve ser contemplado no estabelecimento dos objetivos e metas, enquanto a ISO 14001 é menos prescritiva nesse sentido, determinando que devem ser mensuráveis, quando exequível, e comprometidos com a prevenção de poluição. A Tabela 4 fornece mais detalhes sobre os objetivos e metas para cada sistema.

Tabela 4 - Objetivos e metas dos Sistemas de Gestão ambiental e da Responsabilidade Social

\begin{tabular}{|c|c|}
\hline $\begin{array}{c}\text { ABNT NBR ISO } \\
14001: 2004\end{array}$ & ABNT NBR 16001:2004 \\
\hline $\begin{array}{l}\text { Objetivos, metas e } \\
\text { programa(s) }-4.3 .3 \\
\text { Devem ser mensuráveis, } \\
\text { quando exequível }\end{array}$ & Devem ser compatíveis com a política da responsabilidade social \\
\hline $\begin{array}{l}\text { Comprometidos com } \\
\text { prevenção de poluição }\end{array}$ & $\begin{array}{l}\text { Devem contemplar, mas não se limitar a: } \\
\text { a) boas práticas de governança; } \\
\text { b) combate à pirataria, sonegação, fraude e corrupção; } \\
\text { c) práticas leais de concorrência; } \\
\text { d) direitos da criança e do adolescente, incluindo o combate ao } \\
\text { trabalho infantil; } \\
\text { e) direitos do trabalhador, incluindo o de livre associação, de } \\
\text { negociação, a remuneração justa e benefícios básicos, bem } \\
\text { como o combate ao trabalho forçado; } \\
\text { f) promoção da diversidade e combate à discriminação (p. ex.: } \\
\text { cultural, de gênero, de raça/etnia, idade, pessoo com deficiência); } \\
\text { g) compromisso com o desenvolvimento profissional; } \\
\text { h) promoção da saúde e segurança; } \\
\text { i) promoção de padrões sustentáveis de desenvolvimento, } \\
\text { produção, distribuição e consumo, contemplando fornecedores, } \\
\text { j) prestadores de serviço, entre outros; } \\
\text { k) ações sociais de interesse público. }\end{array}$ \\
\hline
\end{tabular}

É no momento do estabelecimento dos objetivos e metas do sistema, que a organização tem a oportunidade de ir além dos requisitos legais aplicáveis, e incorporar outros que demonstrem seu compromisso com requisitos socioambientais que julgar mais importantes, ou, ainda, os que forem requeridos por seus clientes (mercado) e sociedade na qual está inserida.

Um requisito bastante importante, em ambos os sistemas, para assegurar a eficaz implementação de um SG, é o que diz respeito à "Comunicação". É necessário que a organização estabeleça, implemente e mantenha procedimento(s) para: a) 
comunicação interna entre os vários níveis e funções da organização; b) recebimento, documentação e resposta às comunicações pertinentes oriundas das partes interessadas externas. Em particular, a ISO 14001 (Anexo A, A.4.3) esclarece que o procedimento pode incluir um diálogo com as partes interessadas e considerar suas preocupações pertinentes. Recomenda-se, ainda, que esses procedimentos também tratem da comunicação necessária com as autoridades públicas relativamente ao planejamento de emergência e a outras questões pertinentes.

Em ambos os sistemas, a organização deve estabelecer, implementar e manter procedimento(s) para tratar as nãoconformidades reais e potencias, e executar ações corretivas e preventivas. Deve, ainda, assegurar que auditorias internas do sistema sejam conduzidas, em intervalos planejados, para determinar se o sistema está em conformidade com as disposições planejadas. Os resultados dessas auditorias devem ser informados à alta Administração da organização, a qual é responsável por analisar o SG, em intervalos planejados, para assegurar sua contínua pertinência, adequação e eficácia.

Todos os procedimentos e registros necessários para a implementação e manutenção de um SG são peças fundamentais para a sua avaliação, quando de uma auditoria externa (no caso de certificação voluntária). Esses mesmos documentos podem auxiliar os órgãos competentes, quando de uma fiscalização, fornecendo informações extremamente relevantes, em um menor tempo, de forma estruturada, facilitando 0 processo de maneira geral.

\subsection{Sistemas da Gestão Ambiental e da Responsabilidade Social versus Protocolos privados}

Apesar de possuírem características totalmente distintas (os SG não estabelecem critérios específicos de desempenho, enquanto os protocolos sim), verifica-se que o mínimo que deve ser contemplado, no estabelecimento dos objetivos e metas, quando da implementação da NBR 16001, engloba questões também constantes nos protocolos privados apresentados anteriormente. Devido ao protocolo Bonsucro apresentar redação sucinta, optou-se por utilizá-la, de forma que representasse as exigências comuns aos três protocolos. A Tabela 5 possibilita essa constatação. 
Tabela 5 - Comparação entre a ABNT NBR 16001:2004 e os Protocolos privados

\begin{tabular}{|c|c|}
\hline ABNT NBR 16001:2004 & Bonsucro / RSB / ISCC \\
\hline $\begin{array}{llll}3.2 & \text { d) } & \text { Comprometimento } & \text { com }\end{array}$ & Cumprir a Lei \\
\hline $\begin{array}{l}\text { 3.3.3 d) direitos da criança e do } \\
\text { adolescente, incluindo o combate ao } \\
\text { trabalho infantil; }\end{array}$ & $\begin{array}{l}\text { Respeitar os direitos humanos e } \\
\text { trabalhistas; }\end{array}$ \\
\hline $\begin{array}{l}\text { 3.3.3 e) direitos do trabalhador, incluindo } \\
\text { o de livre associação, de negociação, a } \\
\text { remuneração justa e benefícios básicos, } \\
\text { bem como o combate ao trabalho } \\
\text { forçado; }\end{array}$ & $\begin{array}{l}\text { Respeitar os direitos humanos } \\
\text { trabalhistas; }\end{array}$ \\
\hline $\begin{array}{l}\text { 3.3.3 i) promoção de padrões } \\
\text { sustentáveis de desenvolvimento, } \\
\text { produção, distribuição e consumo, } \\
\text { contemplando fornecedores, prestadores } \\
\text { de serviço, entre outros; }\end{array}$ & $\begin{array}{l}\text { Gerenciar eficiências de insumos, } \\
\text { produção e processamento de modo a } \\
\text { aumentar a sustentabilidade; }\end{array}$ \\
\hline $\begin{array}{l}\text { 3.3.3 j) proteção ao meio ambiente e aos } \\
\text { direitos das gerações futuras }\end{array}$ & $\begin{array}{l}\text { Gerenciar ativamente a biodiversidade e } \\
\text { serviços do ecossistema; }\end{array}$ \\
\hline $\begin{array}{l}3.2 \text { c) comprometimento com a melhoria } \\
\text { contínua e com a prevenção de impactos } \\
\text { adversos }\end{array}$ & $\begin{array}{l}\text { Melhorar constantemente as áreas-chave } \\
\text { do negócio. }\end{array}$ \\
\hline
\end{tabular}

Similarmente, por meio da Tabela 6, princípios de sustentabilidade, preconizados evidencia-se que a implementação da ISO pelos protocolos privados. 14001 proporciona um SGA alinhado aos

\section{Tabela 6 - Comparação entre a ABNT NBR ISO 14001:2004 e os Protocolos Privados}

\begin{tabular}{|c|c|}
\hline ABNT NBR ISO 14001:2004 & Bonsucro/ RSB/ ISCC \\
\hline $\begin{array}{l}4.2 \text { c) Comprometimento em atender aos } \\
\text { requisitos legais } \\
\text { 4.3.3 Comprometimento com a prevenção } \\
\text { da poluição }\end{array}$ & $\begin{array}{l}\text { Gerenciar eficiências de insumos, } \\
\text { produção e processamento de modo a } \\
\text { aumentar a sustentabilidade; }\end{array}$ \\
\hline $\begin{array}{l}\text { 4.3.1 a)b) Procedimento para identificar } \\
\text { aspectos ambientais e impactos } \\
\text { significativos }\end{array}$ & $\begin{array}{l}\text { Gerenciar ativamente a biodiversidade e } \\
\text { serviços do ecossistema; }\end{array}$ \\
\hline $\begin{array}{l}4.2 \text { b) comprometimento com a melhoria } \\
\text { contínua e com a prevenção de poluição }\end{array}$ & $\begin{array}{l}\text { Melhorar constantemente as áreas-chave } \\
\text { do negócio. }\end{array}$ \\
\hline
\end{tabular}

Constata-se que a única exigência não abordada pelas normas ABNT NBR ISO 14001 e ABNT NBR 16001 é a que diz respeito ao cumprimento da Diretiva UE 2009/28/EC. No entanto, como se trata de uma exigência legal para exportar para o mercado europeu, as empresas interessadas em alcançá-lo devem incluí-la quando da definição dos "Requisitos legais e outros" subitens 4.3.2 e 3.3.2, respectivamente, das normas em questão. 


\section{CONCLUSÕES}

Evidencia-se, diante do exposto, que a implementação do SGA e do SGRS, além de estruturar as atividades da organização e monitorar e controlar seus aspectos e impactos, aproxima a empresa tanto da sociedade, quanto das autoridades públicas, dando transparência a suas ações.

As desvantagens em não implementálos estão diretamente ligadas às barreiras não tarifárias, impostas por países desenvolvidos, e a consequente perda de competitividade e o alcance a mercados mais rigorosos.

Particularmente, $\quad 0 \quad$ setor sucroalcooleiro já vem sendo cobrado pelos mercados internacionais, para demonstrar garantia da sustentabilidade de sua produção de etanol por meio da certificação.

A proliferação de certificações privadas, baseadas em protocolos não harmonizados e, muitas vezes, discutidos em fóruns pouco representativos, só confunde o setor produtivo. O produtor precisará se adequar a diferentes protocolos, de acordo com a exigência do país importador, onerando seus custos.

A adoção da norma ISO sobre "Critérios de sustentabilidade para a bioenergia", após sua publicação, configurase em uma importante oportunidade para o setor demonstrar a sustentabilidade de sua produção, sendo fundamental a participação na sua elaboração, de forma a influenciar, adequadamente, para coibir qualquer tentativa de impor requisitos com evidentes características de barreiras técnicas ao comércio internacional de etanol.

Conforme demonstrado, a implementação de um sistema da gestão ambiental ISO 14001, integrado a um sistema da gestão da responsabilidade social, com base na NBR 16001, pode fornecer às empresas do setor grande progresso rumo às certificações privadas, que, ao que tudo indica, são inevitáveis.

\section{REFERÊNCIAS}

ASSOCIAÇÃO BRASILEIRA DE NORMAS TÉCNICAS. ABNT NBR ISO 14001. Sistemas da gestão ambiental - Requisitos com orientações para uso. Rio de Janeiro RJ: ABNT, 2004a.

\section{ABNT NBR 16001.}

Responsabilidade Social - Sistemas da gestão - Requisitos. Rio de Janeiro RJ: ABNT, 2004b.

ABNT NBR ISO/IEC 17000: Avaliação de Conformidade - Vocabulário e princípios gerais. Rio de Janeiro RJ: ABNT, 2005.

BONSUCRO. BETTER SUGAR CANE INITIATIVE. Disponível em: <http://www.bonsucro.com>. Acesso em: 10 nov. 2011.

CGEE. CENTRO DE GESTÃO E ESTUDOS ESTRATÉGICOS. Estudo de Sustentabilidade da Produção de Etanol de Cana-de-Açúcar. Subsídios Técnicos para a Agenda Brasileira de Bioetanol. Relatório final. Brasília: CGEE, 2009.

COMPANHIA NACIONAL DE ABASTECIMENTO (CONAB). Acompanhamento da Safra Brasileira: Canade-açúcar. Safra 2010/2011. Brasília: Conab, $2011 . \quad$ Disponível em: <http://www.conab.gov.br/OlalaCMS/uploads /arquivos/11_01_06_09_14_50_boletim_can a_3o_lev_safra_2010_2011.pdf >. Acesso: 04 maio 2011. 
CEBDS. CONSELHO EMPRESARIAL BRASILEIRO PARA

DESENVOLVIMENTO SUSTENTÁVEL.

Visão 2050: A nova agenda para as empresas, 2010. Disponível em: $<$ http://www.cebds.org.br>. Acesso em: 04 fev. 2012.

DENARDIN V. F.; VINTER, G. Algumas considerações acerca dos benefícios econômicos, sociais e ambientais advindos da obtenção da Certificação ISO 14000 pelas Empresas. Disponível em: $<$ http://www.race.nuca.ie.ufrj.br/eco/trabalho s/comu1/4.doc>. Acesso em: 15 jul. 2011.

ÉCOLE POLYTECHNIQUE FÉDÉRALE DE LAUSANNE (EPFL). Roundtable on Sustainable Biofuels - RSB. Disponível em: <http://rsb.epfl.ch>. Acesso em: 10 nov. 2011.

EUA põem fim aos subsídios do etanol depois de mais de 3 décadas. Exame.com, 30 dez. 2011. Disponível em: <http://exame.abril.com.br/economia/agrone gocio/noticias/eua-poe-fim-aos-subsidios-doetanol-depois-de-mais-de-3-decadas>.

Acesso em: 05 jan. 2012.

FAPESP. FUNDAÇÃO DE AMPARO À PESQUISA DO ESTADO DE SÃO PAULO.

Especiais: Pesquisar para exportar. Agência Fapesp, $2010 . \quad$ Disponível em: <http://www.agencia.fapesp.br/materia/1173 1/especiais/pesquisar-para-exportar.htm>. Acesso em: 11 fev. 2010.

GORREN, R. C. R. Biocombustíveis: Aspectos Sociais e Econômicos: Comparação entre Brasil, Estados Unidos e Alemanha. 2009. Dissertação (mestrado em Energia). Universidade de São Paulo, São Paulo, 2009.

HARRINGTON, H. J.; KNIGHT, A. A. implantação da ISO 14000: como atualizar o
SGA com eficácia. São Paulo: Atlas, 2001. $365 p$.

INMETRO. INSTITUTO NACIONAL DE METROLOGIA, NORMALIZAÇÃO E QUALIDADE INDUSTRIAL. Avaliação da Conformidade. 5. ed. [Brasília: INMETRO], 2007. Disponível em: $<$ http://www.inmetro.gov.br/infotec/publicaco es/acpq.pdf>. Acesso em: 25 jul. 2011.

INTERNATIONAL SUSTAINABILITY \& CARBON CERTIFICATION SYSTEM ISCC. Disponível em: <http://www.isccsystem.org/index_eng.html>. Acesso em: 10 nov. 2011.

KUTAS, G.; ZECHIN, M. R. Em busca da globalização. Agroanalysis, São Paulo, v. 28, n. 8, p. 25-28, ago. 2008.

MACEDO, I. C. Situação atual e perspectivas do etanol. Estud. av. [online]. v.21, n.59, pp. 157-165, 2007. Disponível em:

<http://www.scielo.br/pdf/ea/v21n59/a11v215 9.pdf>. Acesso em: 01 ago. 2008.

BRASIL. MINISTÉRIO DO DESENVOLVIMENTO, INDÚSTRIA E COMÉRCIO EXTERIOR (MDIC). Disponível em:

<http://www.mdic.gov.br/sitio/interna/interna. php?area=2\&menu=999>. Acesso em: 04 fev. 2012.

ORGANIZAÇÃO DAS NAÇÕES UNIDAS (ONU). Rio+20: Conferência das Nações Unidas para o Desenvolvimento Sustentável. $2012 . \quad$ Disponível em: <http://www.uncsd2012.org/rio20/about.html >. Acesso em: 04 fev. 2012.

PETERSEN, J. E. Energy Production with Agricultural Biomass: environmental implications and analytical challenges. European Review of Agricultural Economics, 
v. 35 , n. 3, 2008, pp. 385-408.

POPE, J. et al. Conceptualising sustainability assessment. Environmental Impact

Assessment Review, n. 24, p. 595-616, 2004.

SAID, N. A. Empresas e Responsabilidade Social. Disponível em: $<$ http://www.ecoar.org.br/novo/formacao.asp ?str=9>. Acesso em: 27 jun. 2008.

UNIÃO EUROPEIA (UE). Diretiva 2009/28/CE do Parlamento Europeu e do
Conselho, de 23 de abril de 2009. Jornal Oficial da União Européia, UE, 05 jun. 2009. p L 140/16. Disponível em: <http://eurlex.europa.eu/LexUriServ/LexUriServ.do?uri =OJ:L:2009:140:0016:0062:PT:PDF>.

Acesso em: 20 fev. 2011.

VALOR ECONÔMICO. Equívocos nas críticas contra o etanol brasileiro. Valor Economico, ed. 10 abr. 2008. Disponível em: <http://infoener.iee.usp.br/infoener/hemerote $\mathrm{ca} /$ imagens/112810.htm>. Acesso em: 15 maio 2008. 